\title{
The Ethical Discourse: The Female Writing in the Modificated Process of For Jiao Zhongqing's Wife
}

\author{
Xia Zhaoyang, ${ }^{1, a, *}$ \\ ${ }^{1}$ Academy of Chinese Studies, Beijing Language and Culture University, Xueyuan Road, Beijing, \\ China \\ a.zine10000@126.com \\ *Xia Zhaoyang
}

Keywords: $\quad$ For Jiao Zhongqing's Wife, female writing, the ethical discourse

\begin{abstract}
In the early 20th century, the interpretation of the poem "Wei Jiao Zhongqing Qi Zuo" or "For Jiao Zhongqing's Wife" was mainly based on the social context at the time, which, however, might deviate from the original purpose of the female writing in the work. The poem once witnessed several modifications from the late Eastern Han Dynasty to the Southern Dynasties when the development of traditional Confucian code of ethics took off. The rewritings of female writing in literature works were to adapt to the male-dominated moral codes and discourse system at that time. Based on that, the female writing in the poem was processed, and evidence would be that from the perspective of content, the persona of Liu (Jiao's wife) portrayed in the poem changed greatly while characters like Jiao Zhongqing and Mother Jiao (Jiao's mother) were enriched. In addition, some new plots and characters were created for example, Brother Liu (Liu's brother) and Mother Liu (Liu's mother). In regard to the narrative strategy, the processed version intentionally emphasized the absence of "father" and "unrighteousness" of the brother to serve to the plot of suicide for love of Liu. This type of narrative poems conveying both criticism and praise was a tool used to complete and consolidate the ethical discourse and restrain women's influence on men, and it also echoed the traditional view of women passed from the Qin and Han Dynasties which for sure further confined women's free choice.
\end{abstract}

\section{Introduction}

Judging from handed-down documents, "For Jiao Zhongqing's Wife" was firstly recorded in "Yutai Xinyong" or "New Songs from a Jade Terrace" in the Southern Dynasties with the title "An Ancient Poem for Jiao Zhongqing's Wife (combined preface)" which later was seen in Tang Dynasty's "Yiwen Leiju" or literally "Collection of Literature Arranged by Categories" and Song' s "Yuefu Poetry Collection". The academia has long argued about the creation time and formation process of this poem. Liang Qichao in 1924 mentioned in the "Relationship between Indian and Chinese Culture" that the poem might be influenced by "Fo Ben Xing Zan" and was probably created after the Six Dynasties, yet he later responded to Liu Kezhuang's original idea about the "Six Dynasties Theory" in "Beautiful Chinese Works and its History" that "we'd better put this aside." ${ }^{[1]}$ Later in the 1920s and 1930s, the issue of the creation time of the poem still caused hot 
discussions. Lu Kanru in 1925 published "A Textual Research on Peacock Flying Southeast" to explain the influence of Buddhist literature and poems like "Hua Shan Ji" on "For Jiao Zhongqing's Wife", and believed that the poem was firstly appeared in the Southern Dynasty on the grounds that some images described in the work actually occurred in the Wei and Jin Dynasties.

Xiao Difei and others however, insisted on "the Theory of Jian'an and late Han Dynasty". Hu Shi in his work "History of Vernacular Literature" published in 1927 noted that "I believe the creation of 'The Peacock Flies to the Southeast' is probably not far from the time of the story itself... But I am convinced that it took nearly 300 years for the story to be collected in 'New Songs from a Jade Terrace '... During this period, there were some adjustments, and local elements were included, for example, qinglu (green house) and longzifan (a decoration flag in ships). ${ }^{[2]}$ The story mixed thoughts and innovation of many unknown poets, and finally turned into a masterpiece." Until the 1950s, scholars' research on images and obscure sentences from the poem was further promoted based on what it had been done during the May Fourth Movement.

In 2005, Zhang Peiheng made a summary of different ideas about the writing time of the poem in "On the Formation Process and Writing Time of 'An Ancient Poem for Jiao zhongqing's Wife' " that the story appearing in the volume 32 of "Collection of Literature Arranged by Categories" was the version passed down from Jian'an and late Han period which was recorded in "New Songs from a Jade Terrace" called "An Ancient Poem for Jiao Zhongqing's Wife (combined preface)". Considering the insufficient related research materials in the Wei, Jin, Southern and Northern Dynasties, it was quite difficult to give a more accurate and specific creation time about the poem. Yet a reasonable hypothesis would be that "The creation of 'An Ancient Poem for Jiao Zhongqing's Wife' was started in the Eastern Han (probably Jian'an period) and its main part was completed in the Wei, Jin, and Southern Dynasties period."[3]

In the 1920s and 1930s, the arguments about the poem were accompanied by the backdrop that new literature was required to adapt to the new society, and traditional literary works asked for new understandings and interpretations. In order to call for gender equality in the new era, educated women along with a few men adapted "For Jiao Zhongqing's Wife" into plays in the late Qing Dynasty and the early Republic of China, with the hope of making them tools to encourage women at that time to realize the significance of gender equality and fight for their own rights and interests. Afterwards the Republic of China amended the terms about divorce in the Civil Code at the time which were previously stricter with wives, aiming to safeguard women's freedom in marriage and divorce and marking good results of the battle for women. "For Jiao Zhongqing's Wife" at that time was regarded as a work against feudal patriarchy, and Liu Lanzhi's idea for freedom of marriage in the story was well-accepted by independent women and had a far-reaching influence on the interpretation of later texts. Critiques in the 1950s and 1960s mostly had class and national characters, which did not explain the original textual purpose of women writing in "For Jiao Zhongqing's Wife" at the time. Therefore, this article will base on two versions of the poem- one firstly written in the Han and Jian'an period and the other modified in the Southern and Northern Dynasties- to discuss their differences in female writing and further try to reveal the writing strategies and narrative purposes behind the several modifications of the poem for the reference of researchers.

\section{Female Writing in the First Version in Han and Wei Period}

The text was firstly recorded in "Gui Qing", the volume 32 of " Collection of Literature Arranged by Categories" which neither had a title, nor did it possess the detailed plots portrayed in 
"New Songs from a Jade Terrace". Except for the preface, the main body contains only 24 sentences, and the full text is quoted as follows:

In the late Han Dynasty, Jiao Zhongqing's wife, Liu, was driven away by her mother-in-law. A poet at that time was touched by the story, and wrote it down which said:

Southeast the peacock flies,

and every five li it hesitates in flight.

At thirteen I knew how to weave plain silk,

at fourteen I learned to cut clothes;

a fifteen I played the many-stringed lute,

at sixteen recited from the Songs and History .

At seventeen I became your wife,

but in my heart there was always sorrow and pain

You were a clerk in the government office,

I guarded my virtue and was never untrue

At cockcrow I began my work at the loom,

night after night never resting

In three days I turned out five measures of cloth,

but the Great One grumbled at my slowness

It's not that I'm so slow at weaving,

but it's hard to be a bride in your home.

I have an embroidered vest

so lovely it shines with a light of its own

I have double bed curtains of scarlet gauze

with scent bags hanging from each of the four corners

I have a knitted matt made from ivory with fine grain

in which plain silk thread is twisted.

They may be considered cheap and worthless,

but still there welcome the new bride. ${ }^{[4]}$

The first sentence "Southeast the peacock flies, and every five li it hesitates in flight" was believed growing out of works like "A Pair of White Swans" in "New Songs from a Jade Terrace" and " Yan Ge He Chang Xing" in "Yuefu Poetry Collection". For instance, "southeast flies" matches "northwest comes"; and "every five li it hesitates in flight" might borrow from the sentence "every five li it turns back, and every six li it hesitates in flight". In "A Pair of White Swans", the 
reason behind the white swan's hesitation is that "Suddenly exhausted, one swan fail to catch up"[5] while in "Yan Ge He Chang Xing", it is "The female swan is too exhausted to catch up"[6]. The meaning conveyed here basically is that some external factors keep the couple apart which echoes the description that "Liu was driven away by her mother-in-law". This kind of explanation however, cannot make clear the replacement between "peacock" and "white swan". So given that, another guess about the origination of the first sentence in " For Jiao Zhongqing's Wife" is probably more convincing, that is, it came from poems about weaving women. In the volume 65 of "Collection of Literature Arranged by Categories", the subsection "Weaving" under section agriculture mentioned that "Emperor Jianwen of Liang wrote in the poem 'The Wife of the Second Son Weaves Cheap Yellow Cloth' that petals fall down on the steps and an lonely women is working on the loom by her own. Clouds float from the northwest as peacocks fly to the southeast. When she tries to ravel out silk threads, they twine around her wrist. And when she attempts to push another pedal, her clothes is stuck. The bracelet moves along the flying shuttle and her face shines in the setting sun." ${ }^{[7]}$ And in "Taiping Yulan", it also said, "'Gu Yan Ge' writes that peacocks fly to the east without covers to keep warm. Being your wife, my sorrow lingers. Weaving day and night on the loom, I produced a blot of cloth which yet criticized as indolent." [8]

"Gu Yan Ge", typically a four-character poem (Chinese classical poem with four characters each line) shares similarities in style with poetry in Han, and on top of that it compares a peacock to a weaving woman which is much more close to the female writing in "For Jiao Zhongqing's Wife" in "Collection of Literature Arranged by Categories" compared with the metaphor of swan's love story, because Liu in the poem was characterized as a weaving woman who was engaged in handweaving labor within the family under the economic background of the Eastern Han Dynasty. Since the Qin and Han dynasties, women have played a very important role in economic production activities, and their agricultural-related production carried out by the family as a unit touched on all fields of social economy. For example, "Planting Ge (a herb called Pueraria lobata) at the Foot of the Nan Mountain" and "Planting Melons near the Eastern Well" gave a picture of women's agricultural production of various crops. In "Up the Mountain to Pick Miwu (a herb for medical use)", "Across the River to Pick Furong (or Cottonrose Hibiscus) " and " Picking Lotus in Jiang Nan (the south of the Yangtze River)", picking activities were mentioned. "The Meaning of Wedding, the Book of Rites" mentioned that "Wedding is for a couple from different families to become as one. The couple needs to worship ancestors and carries on family name", ${ }^{[9]}$ and Tao Xisheng also said, "Marriage is a matter of two clans. Why does a man choose to marry a woman from another clan? The primary purpose is to take control of labor activities of women. For aristocratic wives, they might not need to work for materials, yet be responsible for housework"[10] In the Western Han Dynasty, low productivity required women to work with men in farming, so there was no clear division of labor between male and female groups. With the improvement of production tools and higher pursuit of fashion, society in the middle and late Eastern Han Dynasty witnessed the rising of cottage industries for handicrafts with women playing a vital role, which can also explain the emergence of poems about silk weaving. For example, "Meeting in the Narrow Lane" mentioned that "The wife of the eldest son weaves satin while the wife of the second son weaves tough silk."[11]; and "Up the Mountain to Pick Miwu" described "The newly married weaves cheap yellow cloth while the ex weaves valuable white cloth."[12] These lines not only reflect female's engagement in labor activities, but also expose male's expectation of female's labor education.

Comparing the female writings in the first version of "For Jiao Zhongqing's Wife" and "Up the Mountain to Pick Miwu", there were some similarities. The core contents of the former one are labor activities and repudiation. After Liu was " driven away by her mother-in-law ", she speaks out 
that "It's not that I'm so slow at weaving, but it's hard to be a bride in your home" which not only highlights conflicts between the wife and the mother-in-law, but also employee's accusation of unscrupulous employer. For the latter one, even though it mentioned that "Good as the new wife is, she is not comparable to the old one". The focus here actually is that "Judging from the weaving products, the newcomer is not as good as the old." Both the poems show the phenomenon that women were materialized as labor machines in the family during the Eastern Han Dynasty. At that time, in the eyes of the husband's family, the core value of the wife was reflected in the ability to create economic value for the family.

Feminist critics, reviewing the literature of traditional patriarchal society, believe that classic (perfect or evil) female images written in male writing are often regarded as demonstrations of what women should or should not be. A case in point would be the character of the first wife depicted in Coventry Patmore's "The Angel in the House" which was believed to be a symbol of perfect woman in the Victorian era. Men used heavy workloads and strict moral standards as tools to imprison women at home, so that women had no time and space to study and innovate and neglected their self-representation. In this way, the power of discourse and moral judgment set a cap on women's value that it could only be realized best inside a family, and conventional feminism believes that ideas claiming women's gender obligations lying in reproduction and housework are the results of the brainwashing on women by Phallus culture in the patriarchal society. ${ }^{[13]}$

Therefore, it can be seen that female writing in the poem "For Jiao Zhongqing's Wife", recorded in "Collection of Literature Arranged by Categories" aims to establish a classic image of housewives, and praises their hardworking under the socio-economic background of the Eastern Han Dynasty. In "Up the Mountain to Pick Miwu", the ex-husband sighed that the new wife was not as good as the ex. And the plot that Liu was sent away in "For Jiao Zhongqing's Wife" also contains suggestions to male group that it would be better to cherish hardworking wives and to female group that to be good wife, they should learn to equip themselves with needed production skills.

\section{The Female Writing Strategy of the Second Version in the Southern Dynasty}

In the centuries from the late Han Dynasty (B.C.202-A.D.220) to the early Southern and Northern Dynasties (A.D.420-A.D.589), due to the lack of handed down documents, it is hard to know about the exact evolving process of "For Jiao Zhongqing's Wife". However, after being collected in "New Songs from a Jade Terrace", the poem finally showed its new look to the public and confirmed its position as a brilliant pearl in the history of Chinese literature. Inheriting the social requirements and restraints towards women in Han, the Six Dynasties Period (A.D.222A.D.589) also embraced some changes in these regards, and there were relatively adequate descriptions of female images. The female writing in "New Songs from a Jade Terrace" shed light on social attitudes on women in the Six Dynasties that was influenced by ideas in Han period which basically had their roots in pre-Qin period, especially the contents concerning Confucian "Rites of Zhou", "Etiquette and Ceremonial " and "Book of Rites".

In the Yin and Shang period, aristocratic ladies had wide access to wars and sacrifice ceremonies, but when it came to Zhou, women were excluded out of political affairs by the claim that "Women have no access to affairs outside the family", and they could only exert their influence in a short-term and indirect way. Through the construction of a male-centered clan system, ethical codes further proposed different requirements for male and female "rituals" in order to regulate the social status of men and women. But inside a clan, "mother" was in a superior position, so in the early ethical codes, female still had their position and power. 
The Han Dynasties is an important period to build the foundation of the feudal ritual system in the next two thousand years. Since the founding of the Western Han Dynasty (B.C. 202-A.D.8), the empress dowagers who were supposed to maintain the imperial power began to take advantage of the power and participate in government affairs. For example, the Empress Dowager Lv in the Western Han and six other empress dowagers in the Eastern Han once overstepped their boundaries to take over political affairs. The existing bureaucratic system was challenged by the rising power of empress dowagers and the clans behind them as well as the expansion of female officials. In addition, royal princesses especially those in the Western Han expanded their economic and political influence aggressively, which also had an impact on the political blocs in a man-dominated society and authority and stability of imperial power. ${ }^{[14]}$

In the Western Han Dynasty, Dong Zhongshu deified the relationship between the two sexes according to the unity of nature and man, and authorized the idea of male superiority to female, said that "Yang is born from husbands while yin supports it as wives $\cdots$.the three cardinal guides are from the providence, so unalterable."[15] Afterwards, Liu Xiang compiled "Biographies of Exemplary Women" to "give advice to emperors" which also pointed out problems and emphasized the importance of women education. The book offered pragmatic, specific examples as standards to evaluate women's virtue, and expressed the idea for selecting concubine that morality was above appearance. Du Qin once said to General Wang Feng that "For a lady, attractive appearance and singing skills are not indispensable". ${ }^{16]}$ Du Ye said, "I once heard that yang is superior to yin, and it is the natural law that the superior is followed and the inferior is included. But inferior as men is, they are yang inside families and superior as women is, they are yin within countries. So 'Book of Etiquette and Ceremonial' illustrates the three obediences and the four virtues of women and makes it clear that mothers should follow sons." [17]

"In fact, since the Confucian outlook on women in the Han Dynasty was constructed, there have always been conflicts between ethical norms and women's thoughts, words and behaviors. On the one hand, rulers must establish ideological and behavioral norms for women through the orthodox Confucian outlook on women; On the one hand, women were also unwilling to submit to those regulations, and some even showed their defiance. ${ }^{[18]}$ For example, being embarrassed by the husband Zhu Maichen's wife asked for a divorce; Zhuo Wenjun eloped with Sima Xiangru and galloped to Chengdu; Feng Yan's wife "did not allow the husband to have concubines". And there are too many similar cases. "People favor high hair bun shaped like a rectangle with a height of one foot." Women at the time suffered less moral restraints in the pursuit of appearance and some images of them were deemed as negative.

As for the Eastern Han Dynasty, in face of the immature ethical system, the literati and officialdom expanded Dong Zhongshu's theory about female inferiority and stressed that women's beauty lied in their obedience and fragility. Ban Gu's "Baihutong" said that "Wives submit to husbands, and ministers serve emperors just as the earth supports the sky which is determined by status. The humble should offer to do things personally, which is the order from the heaven and should be respected". ${ }^{[19]}$ It even tried to deprive women of "defensive tools" and said that "If husbands do bad things, wives are not allowed to leave which is just like that the earth cannot leave the sky. Evil as husbands are, wives cannot leave."[20] In "Lessons for Women", Ban Zhao "educated" women how to serve and please their husbands and parents-in-laws. The book made "comprehensive and systematic regulations about women's moral cultivation and how they can deal with relationship between husbands and in-laws" which teemed with self-depreciation of women. ${ }^{\text {[21] }}$ It repeated that obedience and fragility made a woman beautiful and introduced the female inferiority theory into standards of virtue and aesthetic. With the gradual improvement and 
deepening of the construction of the ritual system, in addition to reflecting reality, poems on female topics in the Han Dynasty were often characterized as indoctrination. Men using their power in social discourse stereotyped women in literature, so as to make the female inferiority theory longstanding in the society's ethical codes.

Comparing two versions of "For Jiao Zhongqing's Wife", the body part of the poem seen today mostly inherited from the second version in the Six Dynasties. The female writing strategies reflected in the modifications are as follows:

\subsection{The Absence of "Father" and the Condemnation of Women.}

In Jin dynasty, the social atmosphere was relatively inclusive, and society attached great importance to women education and encouraged them to fulfill their talents. Male scholar-officials in the Southern Dynasty yet chose to carry on the customs passed down from the Han and continue the restrictions and indoctrination on women. Compared "Up the Mountain to Pick Miwu" written in the Han and Wei period with "For Jiao Zhongqing's Wife", difference can be noticed that in the former story, the couple divorced because of the husband's unfaithfulness while in the latter one the wife was sent away because of the mother-in-law's prejudice, the modifications of which corresponded with the female writing in the Southern Dynasty. So the second version of the poem collected in "New Songs from a Jade Terrace" expanded the plots mentioned in the preface of the first version that Liu was driven away by Mother Jiao. The female writing in the new poem spared no effort to praise Liu and at the same time criticize Mother Jiao's decision which resulted in such a tragedy. Mother Jiao was even regarded as "the source of trouble" in folk narration. More sympathies from readers went to Liu, more hatreds would come to Mother Jiao. The poem deliberately designed the absence of the "father" to let criticism all targeting at Mother Jiao, which is an essential strategy to set up indoctrinating discourse through reprocessed female writing.

The scholar-bureaucrats constantly adjusted the status of women in the society and country, as well as the constraints and moral requirements on women. Following the path since the pre-Qin period, they managed to construct a historical narrative that all three dynasties (Xia, Shang and Western Zhou) were perished due to women's faults, emphasizing women's negative impact on affairs outside families, and treating women as the bane of political turmoil. ${ }^{[22]}$ From the female writing in "Yuefu Poetry Collection", there are some hints about the perfect feminine characteristics admired in Han that "Women images shaped in the Han Dynasty are mostly generous, tender, honest and gracious". ${ }^{[23]}$ For example, in "Journey to the East Gate" the wife was willing to suffer herself instead of letting her husband to take risks for adventures with the sword; the wife in "Long Xi Xing" was hardworking, tough, and thoughtful; and stories in "The Worthy and Enlightened", "The Benevolent and Wise", and "The Accomplished Speakers" in "Biographies of Exemplary Women" shows that the wives once received education about classics, they possessed the ability to offer advice and assist their husbands. From Han to Jin, women with wisdom and integrity caught the public's attention and became typical examples of female characters in literature to remind future generations.

As for the Jin Dynasties (A.D.266-A.D.420), aristocratic women, like some male personages, challenged the ethical norms established since the Han Dynasty. For example, during the reign of Emperor Wu and in the Taishi era, the crown princess bribed ministers and interfered in the affairs of the court. Zhao Can said, "Crown Princess Jia is young. Jealousy is natural for women, and it will get better as time goes by.".[24] The social atmosphere at the time was open and many women stood out from the crowd because of their talents and went down in the history. Since Jin, stories of some empresses and concubines were written down in biographies, most of who were acclaimed as 
"knowledgeable", "smart", "excellent in writing", "skilled in composing" and so on. And "A New Account of the Tales of the World", also known as "Shi Shuo Xin Yu" used a chapter called "Virtuous Beauties" to document episodes of virtuous and intelligent women. In the Eastern Jin Dynasty, aristocratic families attached great importance to women's education. Xie Daoyun was extolled as genius because of her excellent simile about snow. Besides her, there were also many other highly talented women with scholar demeanor who monitored the men around them and sent help. For example, " 'Why don't make progress any longer?' governor Wang Ningzhi's wife asked Xie E, 'is it due to your dwelling on secular chores or limitations on talents?"'. "Xie E thinks highly of his elder sister Xie Daoyun while Zhang Xuan highly appreciates his younger sister who Zhang believes is comparable to Xie Daoyun. A Buddhist nun named Jini is an acquaintance of the two families and was asked about her opinions about the two. She replied, 'Mrs. Wang (Xie E's sister) looks relaxed and elegant like an eremite; and Mrs. Gu (Zhang Xuan's sister) is kind and pure, a role model among women."'[25]

Mrs. Liu, the wife of Xie An in the Eastern Jin Dynasty, "cannot tolerate her husband to have other concubines." Then here came the classic scene: Mrs. Liu's nephews conveyed the message (the husband's wish for taking concubines) to her and said that works like "Guan Jv" and "Zhong Si" spoke highly of not being jealousy. After hearing what they said, Mrs. Liu understood the implication and asked back who wrote these poems? They replied Zhou Gong. And then Mrs. Liu responded, "That's the reason. The writers were men so they promoted ideas like this. If it was written by the wife, there would not be comments like this."[26] The remark shows that "Mrs. Liu is keenly aware of the male discourse's domination in literary classics like 'The Book of Songs"'. ${ }^{27]}$ The Jin society showed its tolerance and acceptance towards women which to some degree imposed restrictions on men's options. "Jealousy" is supposed to be a common mentality in people's minds, "but for three thousand years, men enjoy extreme freedom which makes it hard for them to feel the same way." ${ }^{28]}$ So being jealous became a label attached to women. Yu Tongzhi in the Southern Dynasties complied women stories in Jin about jealousy into a book called "Jealousy Stories", and Mrs. Liu's story was included. The book ignored women's talents and wisdom and was used to educate women by negative examples. In the trend of "reflecting" the idea that loose restraints on women in the Jin Dynasties caused "bad social impact", "For Jiao Zhongqing's Wife" in "New Songs from a Jade Terrace" finally took in shape after a hundred years of reprocessing.

Characters in the poem like Mother Liu, Brother Liu and matchmaker were produced through later reprocessing which never existed in the preface of the version in "Collection of Literature Arranged by Categories", and Jiao Zhongqing and Mother Jiao in the first version did not have dialogues but their images were enriched through centuries of modifications. So it can be seen that the absence of "fathers" in the two families is not a coincidence, but a deliberate design during reprocessing, with the hope to achieve narrative criticism and avoid judgments to the "fathers" in the sense of ethics. When "mothers" who believed to be virtuous use their power, the basic principle for them would be safeguarding the long-term domination of male group. From lines like "This other must be sent away at once. Send her off and don't dare detain her!"; "I've wasted kindness enough on her already-you'll never have my permission for this!"; and "The family to the east have a virtuous daughter, her beauty the boast of the whole city. Your mother will arrange for you to have her, it will be done in the space of a day!", we can know that Mother Jiao presents three times in the story, and the first and the last happen in the conversations with the son while the second one is with the wife which deprives the son's involvement in the conversation and directly control his decision and desire. Mother Liu appears three times as well, in the first two of which she successively turns down county magistrate's and prefecture's wish for marriage alliance. Yet she fails to show up when Brother Liu persuades Liu into remarrying, and only presents herself the day 
before the wedding and urges the daughter to get the wedding dress ready. Her compromise as a matter of fact, connives the brother's "unrighteousness" and undermines the long-term interests of male indirectly. So rewriters and Liu Xiang hold similar education purpose that women in power are the ones to be under fire.

\section{2. "Brother's Unrighteousness " and Patriarchal Ruling}

Wang Fu mentioned that "Some widows both have sons and daughters as well as great fortunes. They are committed to their marriage the whole life and desire to bury together with their husbands after death. With a death wish, these widows get rid of the force of remarrying. But for some, they might be forced to remarry by immoral and unrighteous uncles or brothers who covet the widows' large dowries and the fortunes of the family or even take their sons as labor force. Suffering from the compulsion, some widows commit suicide by hanging or poisoning themselves, and leave their children. Forcing women to get remarried is nothing short of asking for their suicides." From the Han Dynasty to the Jin Dynasty, widows and women who had been sent away were still under the control of their family. "[29] Unrighteous uncles or brothers" use various means to persuade or coerce them to get remarried, even to dead men. So in contrast, the husband's family's control towards them was relatively limited. The norm here is exactly what the version in "New Songs from a Jade Terrace" criticizes and hopes to change during the reprocessing. Therefore, the reprocessed text expresses opinions through narrative on controversies in the trade of women ownership through marriages of the couples' families.

In the Wei and Jin dynasties, the ownership of women traded through marriages was flexible on the issue of whether to preserve chastity after the death of husband. First of all, when women's marriages are reined by the families, their marital status at the same time would influenced by two clans' power and situations with no doubt, so would the remarriage. ${ }^{[30]}$ "Wang Yin mentioned in "Book of Jin" that Wang Sui, son of Wang Rong intended to marry Pei Dun's daughter. But unfortunately, the son died young, and his father was too sad to let others establish relationship with Pei Dun's daughter. As a result, the daughter unmarried for life. ${ }^{[31]}$ Even though the Peis and the Wangs were well-matched in strength, Pei Dun's prestige personally was no match for Wang Rong's. So the Peis had to accept the result. "Yu Liang's son was killed in the uprising of Su Jun, and the widowed wife, Zhuge Daoming's daughter wanted to remarry. So Zhuge wrote to Yu Liang on this and Yu Liang replied that your daughter is young and it's understandable for a remarriage. But I miss my lost son so much that it was like he just left us." ${ }^{[32]}$ Eventually, the widow got remarried. The Zhuge family was a big name in the Han and Wei Dynasties while the Yu Family in Yingchuan suffered great losses in the uprising and Yu Liang was also affected and weakened, which made him have no choice but to succumb.

Secondly, whether to be faithful to the dead husband depends on individual responses. There are countless examples in Huangfu Mi's "Biographies of Exemplary Women" in which virtuous women vowed not to remarry but later were forced to do so, and chose to injure themselves to show their attitude against remarriages. A case in point is Zhao Song's wife in Hanzhong. After the death of the husband, the wife "painted her face with bluish black color; messed up hairs; and held a knife in her hand, pretending she was insane so that enemies would not hurt her". "Considering her young age and the turmoil in the country, her uncle wanted her to remarry. Zhang Lixiu, the wife however threated not to remarry with her life." [33] After Shu Jingqi's death, "his wife's father Luo Qing asked the daughter to remarry to a person from the same county, but Gongluo wrote to her parents explaining her decision of being single and did not get remarried for many years. ${ }^{[34] " X i a n g d e n g ' ~ s}$ wife cut her hair to show her strong commitment after the husband's death. "The head of the county 
again asked the matchmaker to propose to Zhou Du, but she replied that 'The hair cut has already shown my attitude. Why do you bring up this again?'. Then she took out a knife to cut her nose but was stopped by others. Her acts won the praise of surrounding communities."[35] "After Feng Jizai in Guanghuan died, his wife Ji Er's mother took pity on the daughter which made her find a new husband for her daughter. The daughter however cut the hair to show the refusal and adopted a boy and a girl. She got credit for her choices which were believed following the ethical orders. ". [36] "After the death of Wang Fu in Guanghan, his wife Peng Fei's uncle commanded the niece to remarry to a man called Su Meng. Peng Fei was immersed in grief and made it clear to all the relatives that she did not want a remarriage but failed to be heard. So she shaved her head and became a nun."[37]

"For Jiao Zhongqing's Wife" in the "New Songs from a Jade Terrace" shows the readers that Brother Liu is a representative of "unrighteous brother" when there is no "father", and the character Jiao Zhongqing embodies "husband's ownership" of women. The original background of the poem is that Liu was not widowed but sent away which is hard to modify, but the reprocessed version still created conflicts on "chastity dilemma" which in nature is about women ownership, and its emphasis on the tragedy of Jiao Zhongqing conveys rewriter's idea that Liu's remarriage violates the social requirement of "chastity" and father or brother's denial of husband's absolute ownership of wife is short-sighted and impairs the long-term interests of the male group. Brother Liu said, "Your lot would be as different as heaven from earth - you could assure yourself of a brilliant future! If you do not marry this fine gentleman, how do you intend to get along?" He believed that to "marry a fine gentleman" is a top priority of women and marriage is the only way and necessary method to realize women's values. If Liu is materialized, it can be seen that the female writing in " New Songs from a Jade Terrace" obviously contains a discussion on the legality of women's ownership, and rewriters share their conclusion through the narrative text that as long as the couple gets married, the wife should always follow the husband and the husband's family holds the power to decide where the wife should go and what she should do. Through marriages, the empowerment to the husband consolidates the authority of husband in the society which is also what ethics offer to complete the construction of a male-centered patriarchal society. It is precisely because of the absence of the "father" that the conflict between patriarchy and the authority of husband is avoided, which is also resulted from rewriters' consideration.

\subsection{The Death of Jiao and Liu and Dhastity Restriction}

"Shoujie" was originally a moral criterion for "gentlemen" in the Wei and Jin Dynasties and before. "Zhufan, the king of Wu was about to end the mourning, and planned to let his younger brother Jizha succeed to the throne. Jizha declined and said, "After the death of Duke Xuan of Cao, dukes and people of Cao disagreed on the succession of Duke Cheng of Cao and instead favored Zizang who later left Cao. So without other alternatives, Duke Cheng of Cao eventually came into power. The gentleman says, 'People should Shoujie (behave with integrity).' According to the rituals, Zhufan would be the one to the throne. How can we offend the real duke? To be the head will violate my principles. Although I'm far behind Zizang, I want to learn from him and stick with my integrity." Jizha said that Zhufan as the oldest son should come into power, and if he himself succeeds to the throne, then he will be the one who violates the ethical codes and misbehaves. So his refusal actually shows that he has strictly followed the courtesy requirements of a gentleman.

"In the Han Dynasty, although the court used official positions to praise chastity, and people like Liu Xiang, Ban Zhao wrote to beat the drum for chastity, the society did not take chastity that seriously. No one would prevent women getting remarried, and some men were willing to marry 
them, which proved that the Han Dynasty was just a transitional time which witnessed the change of social attitude towards chastity from loose to strict."[38] This shows that education and advocacy about chastity target at the freedom of remarrying among the public. For example, Zhu Maichen's wife remarried after leaving him. Cai Yong's daughter Cai Wenji remarried many times and even had babies for Hu people (the Northern barbarian tribes in ancient China). "Cao Cao is a close friend of Cai Yong who pities Cai without child accompanying him. So Cao dispatches envoys to trade the daughter back with gold and jades who later remarried to Dong Si.". ${ }^{39]}$ Deng Yuanyi's exwife was sent away by her mother-in-law and later remarried to Ying Huazhong in the Eastern Han. "Huazhong became Dajiang (an official title). His wife took a ride in the vehicle granted by the court. Standing along the street, Deng Yuanyi saw her and said to others that 'She is my ex-wife. She did not do anything wrong. It was my mother who treated her badly. I always think highly of her."'[40] Many more cases related could be enumerated in Han Dynasties, and remarriage was not disgraceful.

In the Western Han Dynasty, Liu Xiang compiled " Biographies of Exemplary Women" and he "collected stories about virtuous imperial concubines and women in the public from 'The Book of Songs' and 'The Book of Documents'; stories happened in prosperous countries or prominent families which were believed to be educational and stories about concubines and rebellious women. ${ }^{[41]}$ Compiled in order, the book totals 8 volumes and aims at giving advice to emperors". The book was divided into eight parts including Matronly Models, the Worthy and Enlightened, the Benevolent and Wise, the Chaste and Obedient, the Principled and Righteous, the Accomplished Speakers, Depraved Favorites, and Supplemental Biographies. Among them, the Chaste and Obedient emphasizes women's faithfulness and obedience to husbands, and the Principled and Righteous focuses more on women's commitment of not getting remarried even with a sacrifice of life. These two parts included thirty stories and they showed some of the requirements of women's virtues. In the story "Mrs. Xi", the country Xi was defeated by Chu and Mrs. Xi was captured by the king of Chu. When Mrs. Xi got the chance to see the king of Xi, she committed suicide and the king followed too. "The king of Chu thought Mrs. Xi was a virtuous woman and ordered to let the couple buried together with the rituals of a duke. ${ }^{[42]}$ This story also became the source of virtuous women who pursue suicide to keep chastity. When describing the scenario that a couple separates apart due to uncontrollable factors, Liu Xiang portrays the plot with moral purpose that the wife kills herself first then the husband follows. It is obvious that as for the fact of double suicide, the focus is diverted from two-way relationship of "a righteous couple" like what has established in "The Meaning of Wedding, the Book of Rites" to more responsibilities of women. The "righteousness" gradually evolves from a two-way moral requirement for a couple to moral burden and criterion only shouldered by women. The idea also helped the moral construction of women's death for love. the character Liu in the second version was a typical example.

Against the background of the long-term social darkness, turmoil and unstable ritual system in the Wei and Jin Dynasties, people began to call for the strengthening of morality, hoping for a more stable ethical system structure to reduce uncertainties in the society. Therefore, the society unconsciously followed the tradition of objectifying and depreciating women in the Wei, and based on restraints of "chastity" on both men and women, people's potential wills were further expressed which to some degree, was at the cost of partial social rights of women. "Books of the Later Han Dynasty: Biography of Women" in the Southern Dynasties mentioned, "Women's virtues have been long discussed in 'Classic of Poetry' and 'Book of Documents'. Talented and virtuous imperial concubines assisted emperors in politics; intelligent women knew well of how to make the family prosperous. Gentlemen promoted honesty and morality while virtuous women at the same time highlighted personal integrity. But from historical classics, records about these women were 
nowhere to be seen. So after the founding of the Eastern Han, women's stories were collected into a biography of women." [43] Among the sixteen women involved in the book, there were four in their stories defending their chastity, three of whom took their own life to show the strong commitment. A robber threatened Yue Yangzi's wife with her mother-in-law's life and forced her to commit adultery with him. With helplessness, the wife killed herself; Huangfu Gui's wife was rent away by Dong Zhuo. The wife had a death wish and purposely irritated Dong Zhuo by swearing at him and then "died under a vehicle"; Yin Yu's wife after the death of the husband was compelled to remarry by her father, but she husband died, they were remarried by their father and she hung herself. For Liu Changqing's wife, though she did not choose suicide, she actually cut her ear to show her determination. All these stories obviously raise "chastity" to the level of "righteousness" in the moral restraint of women. Giving up one's own life for righteousness was believed worthy of glorification and high praise.

"To east and west they planted pine and cypress, left and right set out parasol trees. The branches came together to make a canopy, leaf entwined about leaf. And in their midst a pair of flying birds, the kind called mandarin ducks, raised their heads and cried to each other night after night till the hour of dawn." ${ }^{[44]}$ The tragic and mysterious ending in the poem was influenced by the narrative of bizarre novels in the Wei and Jin Dynasties. For example, King Kang in Song Dynasty wanted to keep his retainer Han Ping's beautiful wife to himself. The couple however died for love with a wish to be buried together after death. King Kang was furious and refused, "Let their fellow villager bury them, but keep the tombs afar. The king said, ' Now that you two love each other that much, if you can make the tombs together, I will never stop again.' Within a short time, two trees grew up out from the tombs. And within in ten days, the trees grew so thick that they almost could not be held around with arms. The trunks bent towards each other and got closer and closer. Their roots were intertwined together and branches interlaced. Two mandarin ducks, one male, the other female perched long on the trees and lingered day and night. Crossing their necks together, two birds cried. Their sorrowful cry moved people in Song. And the trees were later called by people Xiangsi (acacia) which was regarded as the origin of Xiangsi. People in the south all believed the birds were incarnations of the couple's souls. In Weiyang, there was a wall named after Han Ping, and the ballad about their story was still remembered and sung by people." ${ }^{\text {[45] }}$ Zhang Peiheng believes that only when "The trunks bent towards each other" can "The branches came together to make a canopy, leaf entwined about leaf." which means the supernatural plot in the second version of the poem should be affected by this story.

When reprocessing the poem, some scholars in the Southern Dynasties were dissatisfied with the open atmosphere towards women in the Jin Dynasty. For the construction of ethical discourse, they incorporated the elements of the bizarre literature of the Six Dynasties on the basis of the story of the lady of Xiguo, blasting remarriage and strong maternal power which reflects the interaction between the social atmosphere and ethics under the condition of societal changes in the period of Han, Wei, Southern and Northern Dynasties. The ethical discourse employs supernatural plots to portray Jiao and Liu's love story and at the same time bashes villains like Mother Jiao and Brother Liu, further deepening the theme on chastity. Attempts to set up this moral standard have been made throughout the Han, but it is still not solid enough as social atmosphere varies from time to time. Therefore, scholars since the Wei and Jin Dynasties have repeatedly written works to strengthen it.

\section{Conclusions}

The centuries from the Han Dynasty to the Southern and Northern Dynasties were an important period in Chinese history for the popularization of "Rites of Zhou" to establish and perfect ethical 
system. The basic principles of the Confucian ritual system during the Han dynasty shaped the ritual discourse system. And after Eastern Han Dynasty, literati and officialdom were inclined to realize moralization in a top-down way to make sure morals' regulation and management over all classes in the entire society. Since the Pre-Qin Period, there have been relatively complete moral evaluation standards for male behaviors. So since the Western Han Dynasty, scholar-officials have turned their attention to women and managed to expound the moral discourse system required by the ethics through the definition of the relationship between emperors and courtiers, fathers and sons, and men and women. Female works during this period mostly had their authors unknown, and some of them were written by women while most of the works were mainly made by men, which meant that the "positive" images of women in them were the ones that appreciated and praised by men in different periods. After the Jin Dynasty, the literary world began to pay more attention to the shaping of negative examples, and tried to use criticism and compliments as a combination to promote further development of the system of ethical discourse.

During those centuries, it was precisely because the restraint and imprisonment of ethics on women has not been completely established and perfected, the consolidation and supplement never stopped their development. This paper compares the differences in female writing between the first version of "For Jiao Zhongqing's Wife" in the Han and Wei Dynasties and the final version in the Southern Dynasties, considers the attitude changes of male scholars towards women indicated through literature and believes the reprocessing of the poem was conducted to adapt to the ethical discourse by greatly altering the character Liu. Especially, Liu who focused on weaving in the first version was changed into a character paying more attention on "chastity"; the appearance of Brother Liu and more descriptions on Mother Jiao are used to criticize women with power and unrighteous men. The tragic result is amplified and characters become more typical and impressive. The modifications showed in the second version unveils that the man-dominated society in the Southern Dynasties hoped to restrain women and consolidate ethical discourse and education by creating dramatic and vivid tragedies of "love".

\section{References}

[1]Liang Qichao (1996) The Beautiful Literature of China and Its History, Oriental publishing house, 87.

[2]Hu Shi (1999) History of Vernacular Literature, Shanghai Ancient Books Publishing House, 62.

[3]Zhang Peiheng (2005) On the Formation Process and Writing Age of Ancient Poems Written for Jiao Zhongqing's wife, Journal of Fudan University (SOCIAL SCIENCE EDITION), 4,2-9+27.

[4]Ouyang Xun (1985) Collection of Arts and Culture, Vol. 1, Shanghai Ancient Books Publishing House, 562. The translation refers to Burton Watson (1984) The Colimbia Book of Chinese Poetry, Columbia University Press, 9192.

[5]Xu Ling, ed. Wu Zhaoyi, et al. Note (1985) Notes on Yutai New Yongjian, Vol. 1, Zhonghua Book Company, 15.

[6][Guo Maoqian (1979) Yuefu Poetry Anthology, Zhonghua Book Company, 576.

[7] Ouyang Xun (1985) Collection of Arts and Culture, Vol. 1, Shanghai Ancient Books Publishing House, 1167.

[8]Li Fang, Xia Jianqin, et al. (1994) Book 7: Taiping Yulan, Hebei Education Press, 685.

[9]Zheng Xuan, Kong Yingda (1999) . Book of Rites, Justice, Hunyi, Peking University Press, 1618.

[10]Tao Xisheng (2015) An Analysis of the History of Chinese Society (another: marriage and family), commercial press, 204.

[11]Xu Ling, ed. Wu Zhaoyi, et al. Notes (1985) Notes on Yutai New Yongjian, Vol. 1, Zhonghua Book Company, 10. 
[12]Xu Ling, ed. Wu Zhaoyi, et al. Notes (1985) Notes on Yutai new Yongjian, Vol. 1, Zhonghua Book Company, 1.

[13]Fu Meirong (2013) Representation / Anti-Representation: The Occurrence of Feminist Criticism, Journal of Jishou University (SOCIAL SCIENCE EDITION), 2,90-95 .

[14]Chen Liping (2010) The Political Crisis and the Concept of Female Disaster in Han Dynasty, Yunnan Social Sciences, 1, 132-135+160.

[15]Su Yu (1992) Chunqiu Fanlu Yizheng • Jiyi, Zhonghua Book Company, 351.

[16]Ban Gu (1962) Biography of Du Zhou in Hanshu, Zhonghua Book Company, 2688.

[17]Ban Gu (1962) Biography of Gu Yong and Du ye in Hanshu, Zhonghua Book Company, 3475.

[18]Liu Shuli (2008) Women's View in Pre-Qin, Han, Wei and Jin Dynasties and Women in Literature, Xueyuan publishing house, 131.

[19] Chen Li (1994) Baihutongshuzheng Wuxing, Zhonghua Book Company, 166.

[20]Chen Li (1994) Baihutongshuzheng Jiaqu, Zhonghua Book Company, 467.

[21]Liu Shuli (2008) Women's View in Pre-Qin, Han, Wei and Jin Dynasties and Women in Literature, Xueyuan press, 127.

[22]Xia Zengmin and Chi Mingxia (2012) Confucianism and the theoretical construction of gender system in Han Dynasty: focusing on the historical events of Mo Xi, Daji and Bao Si in the view of women's disaster history, Journal of Huazhong University of science and Technology (SOCIAL SCIENCE EDITION), 4, 94-100.

[23]Xiao Difei (1984) History of Yuefu Literature in Han, Wei and Six Dynasties, People's Literature Publishing House, 73.

[24]Fang Xuanling (1974) Biography of Empress Concubine, Zhonghua Book Company, 964.

[25]Xu Zhenyu (1984) Xianyuan, A Collation of New Aayings of the World, Zhonghua Book Company, 378.

[26]Ouyang Xun (1985) Collection of Arts and Culture, Vol. 1, Shanghai Ancient Books Publishing House, 614.

[27]Liu Shuli (2008) Women's View in Pre-Qin, Han, Wei and Jin Dynasties and Women in Literature, Xueyuan publishing house, 336.

[28]Chen Dongyuan (1984) Life History of Chinese Women, Shanghai Bookstore, 74.

[29]Wang Fu, Wang Jipei (1985) Correction of Qian Fu's Comments on Paper, Duan lawsuit, Zhonghua Book Company, 236.

[30]Dong Shuxin (2018) Research on Love and Marriage Novels of Han, Wei and Six Dynasties, Doctoral Dissertation of Shandong University.

[31]Xu Zhenyu (1984) Notes on Shi Shuo Xin Yu, Mourning the past, Zhonghua Book Company, 349.

[32]Xu Zhenyu (1984) Notes on Shi Shuo Xin Yu, Mourning the past, Zhonghua Book Company, 350.

[33]Li Fang, Xia Jianqin, et al. (1994) Book 4: Taiping Yulan, Hebei Education Press, P. 652.

[34]Li Fang, Xia Jianqin, et al. (1994) Book 4: Taiping Yulan, Hebei Education Press, P. 652.

[35]Li Fang, Xia Jianqin, et al. (1994) Book 4: Taiping Yulan, Hebei Education Press, P. 652.

[36]Li Fang, Xia Jianqin, et al. (1994) Book 4: Taiping Yulan, Hebei Education Press, P. 652.

[37]Li Fang, Xia Jianqin, et al. (1994) Book 4: Taiping Yulan, Hebei Education Press, P. 653.

[38]Liu Shuli (2008) Women's view in Pre-Qin, Han, Wei and Jin Dynasties and Women in Literature, Xueyuan publishing house, 55. 
[39]Notes by Fan Ye and Li Xian (1965) Biographies of Women in the Later1Han Dynasty, Zhonghua publishing house, 2800.

[40] Gan Bao (1991) SouShen Ji, Volume 11, Guizhou people's publishing house, 331.

[41]Ban Gu (1962) Biography of Chu Yuan King in Hanshu, Zhonghua Book Company, 1957.

[42]Zhang Jing (1994) Translated and Annotated: Notes and Translations of the Biographies of Women, Taiwan Commercial Press, 144.

[43]Fan Ye, Noted by Li Xian et al (1965) Post-Han Book : Biography of Women, Zhonghua Book Company, 2781.

[44]Xu Ling, ed. Wu Zhaoyi, et al. Notes (1985) Notes on Yutai New Yongjian, Vol. 1, Zhonghua Book Company, 53.

[45]Gan Bao (1991) SouShen Ji, Vol. 11, Guizhou people's publishing house, 326. 